\title{
Caracterização Morfológica Utilizando Imagens de Satélites
}

\author{
PEREIRA, Paulo Tibúrcio ${ }^{1}$; SOUZA JÚNIOR, Moacir de ${ }^{2}$ e RAMOS, Gláucio Lopes ${ }^{3}$ \\ ${ }^{1,2,3}$ Centro Universitário de Belo Horizonte - UNIBH \\ Departamento de Ciências Exatas e Tecnologia - Engenharia Elétrica \\ Avenida Professor Mário Werneck 1685 - Belo Horizonte, Estoril CEP: 30455-610 \\ E-mail: ptiburcio@acad.unibh.br ${ }^{1} \underline{\text { moacir.junior@unibh.br }}^{2}$, glopesr@gmail.com ${ }^{3}$,
}

\begin{abstract}
Resumo - Este artigo apresenta uma técnica de caracterização morfológica utilizando imagens de satélites. A caracterização morfológica possibilita mapear os recursos naturais de uma região. Imagens digitalizadas provenientes do sensor $\mathrm{ETM}^{+}$do satélite Landsat-7 foram utilizadas e geoprocessadas pelo software Spring. O geoprocessamento foi realizado em quatro etapas: georeferenciamento, composição das bandas, segmentação e classificação. Foi realizado o mapeamento morfológico da região de Foz do Iguaçu - PR. A técnica utilizada apresentou resultados satisfatórios no que concerne à exatidão e à qualidade das imagens.
\end{abstract}

Palavras - chave: mapeamento, imagens de satélites, caracterização morfológica.

Abstract - This article presents a technique of morphologic characterization using satellites images. Morphologic characterization allows the mapping of natural resources of a region. Digital databases from sensor $\mathrm{ETM}^{+}$of the Landsat-7 satellite were used and processed by Spring software. The image processing was executed in four stages: rectification, band composition, segmentation and classification. The morphologic mapping of the Foz do Iguaçu - PR region was carried through. The technique presented satisfactory results with respect to the precision and images quality.

Keywords: mapping, satellites images, morphologic characterization.

\section{INTRODUÇÃO.}

As imagens de satélites obtidas através do sensoriamento remoto possibilitam ao homem obter informações acerca dos recursos naturais renováveis, nãorenováveis, uso e ocupação do solo do nosso planeta. Entretanto, esta tecnologia requer o conhecimento dos vários componentes que constituem este sistema.
O satélite Landsat-7 [1] e [2] faz parte do grupo de satélites utilizados para monitoramento e estudo do meio ambiente.

Ele está equipado com o sensor $\mathrm{ETM}^{+}$que pode captar imagens em oito bandas do espectro eletromagnético. A utilização dos dados captados pelo sensor orbital $\mathrm{ETM}^{+}$ possibilita o mapeamento morfológico de uma determinada região.

Essa tecnologia tornou-se, para a comunidade científica, uma importante ferramenta de caracterização do nosso planeta que é empregada em diversas áreas da Ciência, como na Engenharia, na Geografia e na Geologia.

\section{OBJETIVO DO TRABALHO.}

Utilizar as imagens digitais das bandas 3, 4 e 5 do sensor $\mathrm{ETM}^{+}$do satélite Landsat-7 que permitem realizar a classificação morfológica para o mapeamento dos recursos naturais, do uso e da ocupação do solo.

Neste trabalho foram utilizadas as informações contidas nas imagens digitalizadas das bandas 3, 4 e 5 do sensor $\mathrm{ETM}^{+}$do satélite Landsat-7 livre da cobertura de nuvens e, através do software Spring [3] e [4], processadas.

As imagens foram georeferenciadas, combinadas, segmentadas e classificadas de modo a propiciar o mapeamento dos recursos naturais, do uso e da ocupação do solo da região de Foz do Iguaçu - PR. Foi gerado um mapa composto "RGB" das imagens das bandas 5, 4 e 3 respectivamente e também o mapa temático morfológico. 


\section{DESCRIÇÃO DA REGIÃO EM ESTUDO.}

Em 14 de março de 1914, pela Lei n. ${ }^{\circ}$ 1383 foi criado o Município de Vila Iguaçu que passou a denominar-se "Foz do Iguaçu", em 1918. A cidade de Foz do Iguaçu está localizada no extremo Oeste do Paraná com latitude: $25^{\circ} 32^{\prime} 45^{\prime \prime}$ e longitude: $54^{\circ} 53^{\prime}$ 07".

Ela está a $637 \mathrm{~km}$ de Curitiba e a $1.069 \mathrm{~km}$ de São Paulo. Estima-se hoje uma população de 266.771 habitantes [5]. A localização da região é mostrada na Fig. 1.

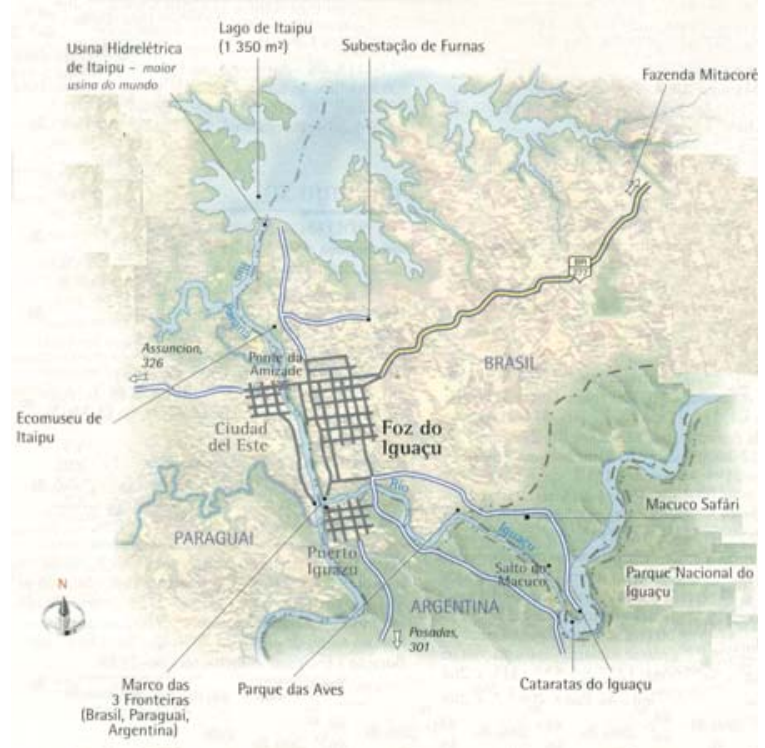

Figura 1. Mapa da Região de Foz do Iguaçu [6].

\section{MetodologiA.}

\section{A. Fundamentação Teórica}

A atmosfera terrestre é indispensável à vida em virtude dos gases que contém e por ser um filtro protetor de radiações solares com alto poder de penetração, como a radiação ultravioleta e os raios $\mathrm{X}$.

As regiões do espectro eletromagnético, para as quais a radiação não é absorvida são denominadas de "janelas", conforme é mostrado na Fig. 2.

Quando a radiação de determinados comprimentos de onda é pouco atenuada pela atmosfera, define-se aí uma janela atmosférica para esta radiação.

Observa-se na Fig. 2 que as radiações de comprimentos de onda entre $100 \mu \mathrm{m}$ e 1 $\mathrm{mm}$ são todas absorvidas pela atmosfera terrestre. Neste caso, não são utilizados sensores para medir essas radiações, pois nenhuma quantidade chegaria a eles.

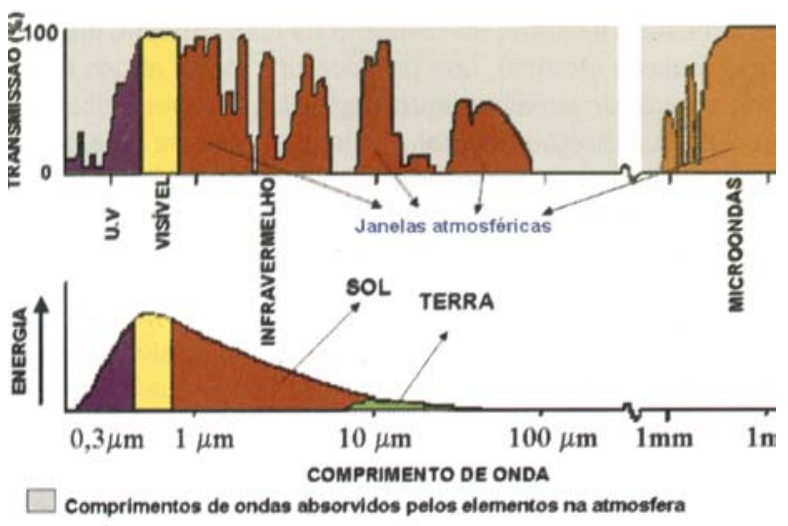

Figura 2. Janelas espectrais da atmosfera terrestre [1].

A radiação eletromagnética interage com os alvos da superfície terrestre podendo ser absorvida, refletida, transmitida e emitida por eles seletivamente. A interação da radiação eletromagnética com os alvos na superfície da Terra e com o próprio solo depende das características de cada um dos alvos e do meio ambiente que os cercam.

As condições do meio ambiente são responsáveis pela atenuação da energia no percurso da radiação do alvo até onde é quantificada. É possível medir, com razoável precisão e distância, as propriedades espectrais dos alvos $\mathrm{e}$ fenômenos da superfície terrestre.

Essas medidas podem ser obtidas por meio dos sensores.

O pixel representa a média das energias refletidas pelos alvos na superfície terrestre dentro de um IFOV (Campo de visada instantâneo) [1]. Isso quer dizer que não há possibilidade de separar as energias de cada alvo dentro do pixel, conforme mostra a Fig. 3.

A energia solar, ao incidir em diferentes alvos interage com cada um e reflete uma quantidade, que depende do alvo.

A energia que sai de cada um desses alvos é captada por um dado sensor num dado ângulo sólido. Ao atingir o sensor, gera-se um único sinal (radiância média), que será representado por determinado valor de cinza, que varia do preto ao branco. 
Valores intermediários dependem da intensidade média da radiação refletida que chega ao sensor.

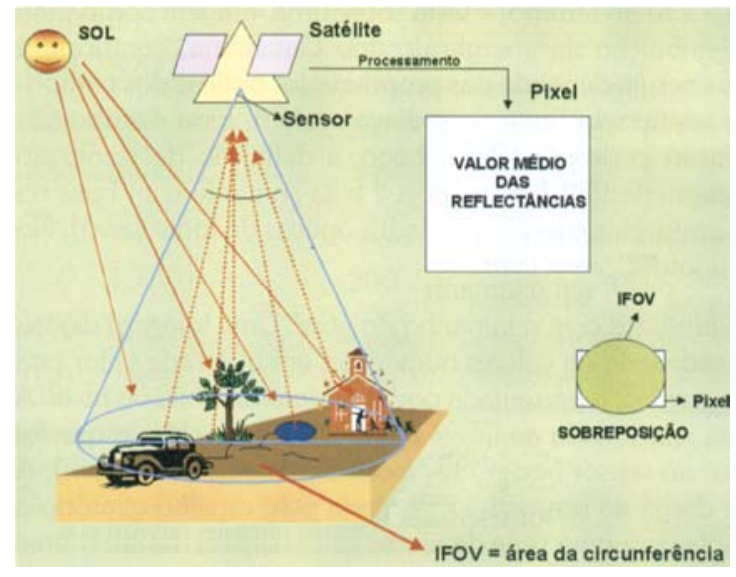

Figura 3. Tecnologia de sensoriamento remoto e geoprocessamento [1].

Conforme é mostrado na Fig. 4, cada alvo tem comportamento espectral diferente na mesma condição ambiental. Observa-se que a água apresenta a mais baixa reflectância e absorve toda a radiação acima de $750 \mathrm{~nm}$.

$\mathrm{O}$ asfalto é quase uniforme e paralelo ao longo do eixo $\mathrm{X}$, não ultrapassando $10 \%$ no valor da reflectância.

Observando ainda a Fig. 4, nota-se que o alvo que mais reflete a radiação no infravermelho próximo é a grama, isto é, cerca de 50\% nesta faixa do espectro eletromagnético.

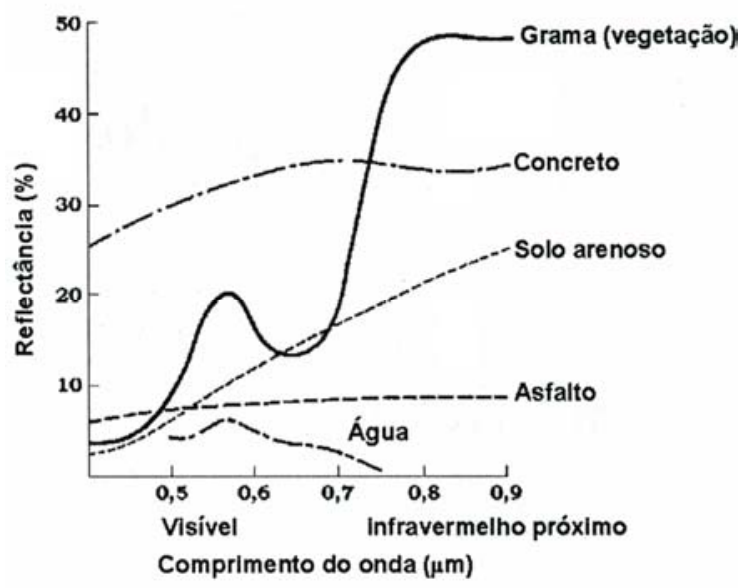

Figura 4. Curvas de reflectâncias para diferentes tipos de alvos [1].
Os diferentes alvos sobre a superfície terrestre refletem a energia solar de maneira diferenciada. Quando os alvos são semelhantes entre si, as energias refletidas por eles são muito parecidas. É o caso de uma área plantada com arroz e outra com trigo, ambas, com a mesma porcentagem de cobertura do solo.

A tonalidade, a cor, a forma, o tamanho e a textura dos detalhes das imagens, obtidas pelos sensores orbitais, são analisadas e processadas para identificar as características do alvo.

A quantidade de energia refletida por uma planta é função de características intrínseca desta, mas pode ser alterada se a planta for submetida a um estresse, causado por desequilíbrio nutricional, déficit hídrico, ataque de pragas e efeitos climáticos adversos.

A partir de 1984, a NASA colocou em órbita os satélites Landsat-4 e 5 equipados com o sensor imageador TM.

Em 1999 foi lançado o satélite Landsat-7 equipados com o sensor $\mathrm{ETM}^{+}$.

$\mathrm{O}$ sensor $\mathrm{ETM}^{+}$opera em oito bandas espectrais, sendo três na região do visível, três na região do infravermelho refletido, uma na região termal e uma pancromática. A largura de faixa imageada é de $185 \mathrm{~km}$.

A resolução espacial do sensor que opera nas regiões do visível e infravermelho refletido é de $30 \mathrm{~m}$ x $30 \mathrm{~m}$, da região do termal é de $120 \mathrm{~m} \mathrm{x} 120 \mathrm{~m}$ e a do sensor que opera na banda pancromática é de $15 \times 15$ $\mathrm{m}$, conforme mostradas na Tabela I.

$\mathrm{Na}$ banda $\mathrm{ETM}^{+}$6, a energia coletada pelo sensor é proveniente de radiação emitida pelos alvos. Dessa forma, a gradação de níveis de cinza dos alvos nesta imagem representa diferentes temperaturas de superfície.

Nos demais casos, a gradação de níveis de cinza refere-se à maior ou menor energia refletida pelos alvos na faixa espectral que opera cada sensor.

No $\mathrm{ETM}^{+}$, cada banda espectral da região do visível e do infravermelho refletido, possui 16 detectores. $\mathrm{Na}$ banda do termal, o 
sensor é composto por um conjunto de 4 detectores.

Tabela I

CARACTERÍSTICAS ESPECTRAIS E ESPACIAIS DO SENSOR ETM $^{+}$DO LANDSAT-7 [1].

\begin{tabular}{|c|c|c|c|}
\hline \multirow{2}{*}{ Banda } & $\begin{array}{c}\text { Região do } \\
\text { espectro }\end{array}$ & $\begin{array}{c}\text { Resolução } \\
\text { espacial m x m }\end{array}$ & Banda \\
\cline { 2 - 3 } & $\mu \mathrm{m}$ & Azul & 30 \\
\hline 1 & $0,45-0,52$ & Verde & 30 \\
\hline 2 & $0,53-0,61$ & Vermelho & 30 \\
\hline 3 & $0,63-0,69$ & IV próximo & 30 \\
\hline 4 & $0,78-0,90$ & IV médio & 30 \\
\hline 5 & $1,55-1,75$ & IV termal & 120 \\
\hline 6 & $10,4-12,5$ & IV médio & 30 \\
\hline 7 & $2,09-2,35$ & VIS IV próximo & 15 \\
\hline 8 & $0,52-0,90$ & & \\
$($ PAN) & & & \\
\hline
\end{tabular}

Além disso, no $\mathrm{ETM}^{+}$a radiância que chega aos detectores é quantizada em 256 números digitais ou níveis de cinza. A resolução temporal é de 16 dias.

\section{B. Processamento das Imagens Digitais}

Foi escolhido para o mapeamento morfológico da região de Foz do Iguaçu as bandas 3, 4 e 5, por serem as mais adequadas para esta finalidade [1] e [7] a [11].

As imagens digitalizadas utilizadas são provenientes da empresa Engesat [12].

As características originais das imagens estão descritas na Tabela II.

Utilizando o software Impima [3] que é um acessório do software Spring [3] e [4] as imagens originais foram recortadas de forma a descartar as informações externas à região de interesse.

No salvamento dos arquivos das imagens, o Impima pode converter as imagens do formato.tif para o formato.grb preparando para o processamento no Spring.

Após está conversão pode-se realizar o registro das imagens. O registro é uma transformação geométrica que relaciona as coordenadas da imagem (linha e coluna) com as coordenadas geográficas (latitude e longitude) de um mapa.
Tabela II

CARACTERÍSTICAS DAS IMAGENS DA REGIÃO.

\begin{tabular}{|c|c|c|c|}
\hline \multicolumn{4}{|c|}{ Características das Imagens da Engesat Utilizadas } \\
\hline Satélite & \multicolumn{3}{|c|}{ LANDSAT-7 } \\
\hline Sensor & \multicolumn{3}{|c|}{$\mathrm{ETM}^{+}$} \\
\hline Orbita/Ponto & \multicolumn{3}{|c|}{$224 / 078$} \\
\hline Data & \multicolumn{3}{|c|}{ 06/07/2000 } \\
\hline Projeção & \multicolumn{3}{|c|}{ UTM } \\
\hline Datum & \multirow{2}{*}{\multicolumn{3}{|c|}{ WGS-84 }} \\
\hline Resolução & & & \\
\hline Fuso & \multicolumn{3}{|c|}{21} \\
\hline Hemisfério & \multicolumn{3}{|c|}{ SUL } \\
\hline \multicolumn{4}{|c|}{ Canto Superior Esquerdo } \\
\hline E & 584255.991 & Lat & $24^{\circ} 58^{\prime} 41.15^{\prime \prime} \mathrm{S}$ \\
\hline $\mathrm{N}$ & 7237218.417 & Long & $56^{\circ} 09^{\prime} 54.73^{\prime \prime} \mathrm{W}$ \\
\hline \multicolumn{4}{|c|}{ Canto Superior Direito } \\
\hline E & 823775.991 & Lat & $24^{\circ} 56^{\prime} 45.27^{\prime \prime} \mathrm{S}$ \\
\hline $\mathrm{N}$ & 7237218.417 & Long & $53^{\circ} 47^{\prime} 38.10^{\prime \prime} \mathrm{W}$ \\
\hline \multicolumn{4}{|c|}{ Canto Inferior Direito } \\
\hline E & 823775.991 & Lat & $27^{\circ} 00^{\prime} 29.49^{\prime \prime} \mathrm{S}$ \\
\hline $\mathrm{N}$ & 7008468.417 & Long & $53^{\circ} 44^{\prime} 14.77^{\prime \prime} \mathrm{W}$ \\
\hline \multicolumn{4}{|c|}{ Canto Inferior Esquerdo } \\
\hline E & 584255.991 & Lat & $27^{\circ} 02^{\prime} 36.41^{\prime \prime} \mathrm{S}$ \\
\hline $\mathrm{N}$ & 7008468.417 & Long & $56^{\circ} 09^{\prime} 01.68^{\prime \prime} \mathrm{W}$ \\
\hline
\end{tabular}

Essa transformação elimina distorções existentes na imagem, causadas no processo de formação da imagem, pelo sistema sensor e por imprecisão dos dados de posicionamento do satélite, conforme a Fig. 5.

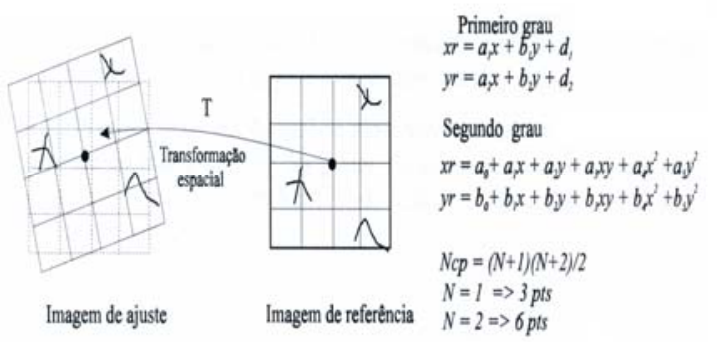

Figura 5. Registro de imagens.

Para a realização do registro das imagens foram utilizados seis pontos de controle. $\mathrm{O}$ mosaico mostrado na Fig. 6 é disponibilizado pelo INPE [13]. Através dele foram obtidas as coordenadas dos pontos de controle.

Com o movimento do mouse ele indica as coordenadas do cursor, utilizando o Datum WGS84 e a projeção LATLONG.

Os pontos da Tabela III foram escolhidos por possuírem feições possíveis de serem identificadas de modo preciso na imagem e no mapa. Na Fig. 7 é mostrada a tela do Spring com os pontos de controle. 


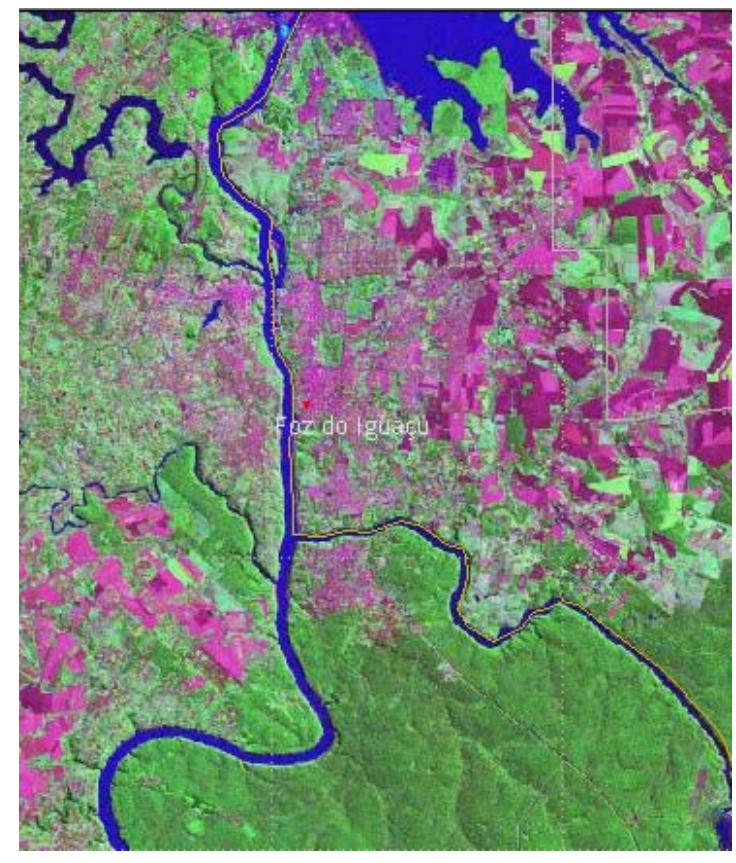

Figura 6. Mosaico do INPE da região em estudo.

Tabela III

COORDENADAS DOS PONTOS DE CONTROLE DA REGIÃO EM ESTUDO.

\begin{tabular}{|c|c|c|c|}
\hline $\begin{array}{c}\text { Ptos. de } \\
\text { Controle }\end{array}$ & Descrição & Latitude & Longitude \\
\hline pc1 & Rio Paraná c/ Iguaçu & s 25 3203 & o 543531 \\
\hline pc2 & Foz no Rio Paraná & s 25 29 46 & o 543557 \\
\hline pc3 3 Margem superior do lago & s 25 2647 & o 543708 \\
\hline pc4 & Meandro & s 25 31 18 & o 543828 \\
\hline pc5 & Margem inferior da ilha & s 252638 & o 543556 \\
\hline pc6 & Braço no lago Itaipu & s 25 2324 & o 543141 \\
\hline
\end{tabular}

Após o registro, as imagens ficam georeferenciadas e cada pixel, contendo uma informação, fica relacionado com uma latitude e longitude.

Foi feita uma operação de distribuição linear realçando nas imagens as três bandas, 3,4 e 5 .

Este realce é uma transferência radiométrica em cada pixel, com o objetivo de aumentar a discriminação visual entre os objetos nas imagens.

A operação é feita ponto a ponto, independente da vizinhança.

Com os contrastes ajustados, foi criada uma imagem sintética da composição colorida, relacionando as bandas 5,4 e 3 com as cores RGB, respectivamente, conforme a Fig. 8.

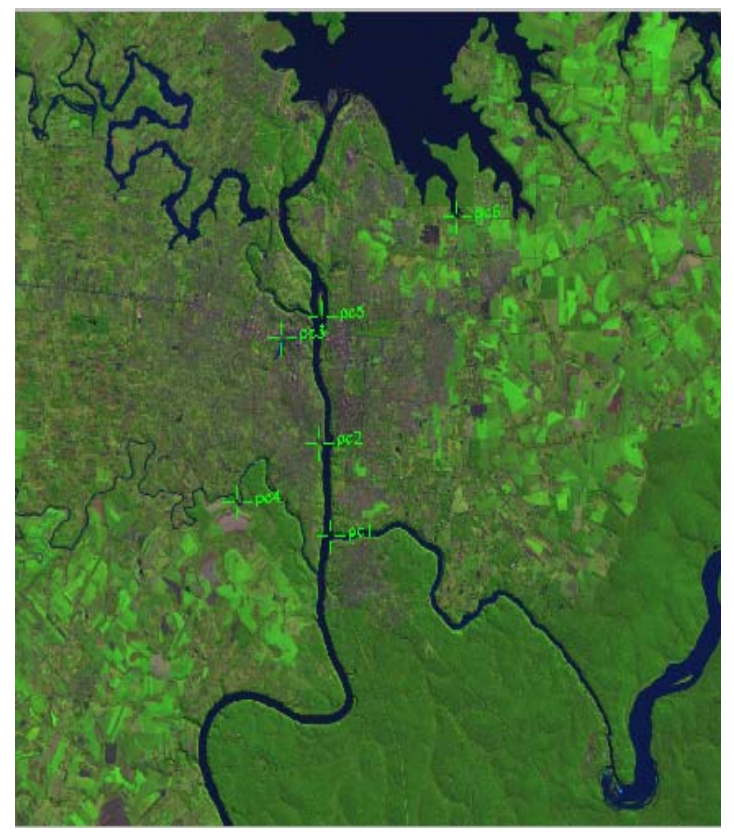

Figura 7. Pontos de controle na região em estudo.

A imagem sintética da composição colorida foi segmentada. Na segmentação, a imagem é dividida em regiões, que são conjuntos de pixels contíguos, que se espalham bidirecionalmente e que apresentam uniformidade.

Para realizar essa segmentação é utilizado um processo chamado de Crescimento de Regiões. Ele rotula cada pixel como uma região distinta.

Calcula-se um critério de similaridade para cada par de regiões adjacentes espacialmente, que é baseado em um teste de hipótese estatístico que testa a média entre as regiões.

A seguir, divide-se a imagem em um conjunto de subimagens e é feita a união entre elas, segundo um limiar de agregação definido.

Na Fig. 9 é apresentada a segmentação da região com zoom.

Após a segmentação, a imagem foi classificada por regiões utilizando o processo Isoseg [4].

Foram selecionados como contexto de classificação os segmentos da imagem sintética composta com os dados das imagens das três bandas: 3,4 e 5 . 
Nesse processo é extraído da imagem informações para reconhecer padrões e objetos homogêneos.

A informação de borda é utilizada inicialmente para separar regiões e as propriedades espaciais e espectrais irão unir áreas com mesma textura. Ele é um algoritmo de agrupamento de dados nãosupervisionado, aplicado sobre o conjunto de regiões, que por sua vez são caracterizadas por seus atributos estatísticos de média, matriz de covariância e pela área da região em estudo.

Na Fig.10 é mostrada a região classificada.

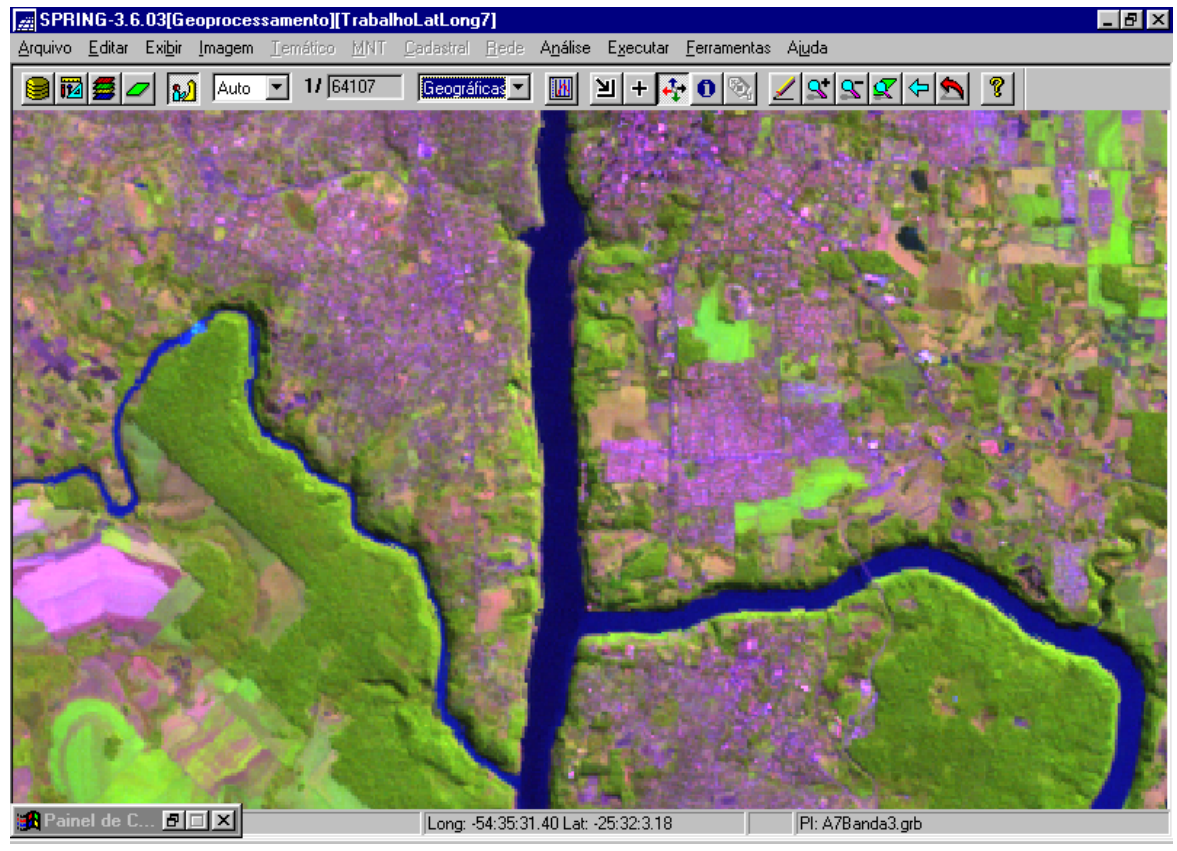

Figura 8. Imagem sintética da composição colorida com zoom.

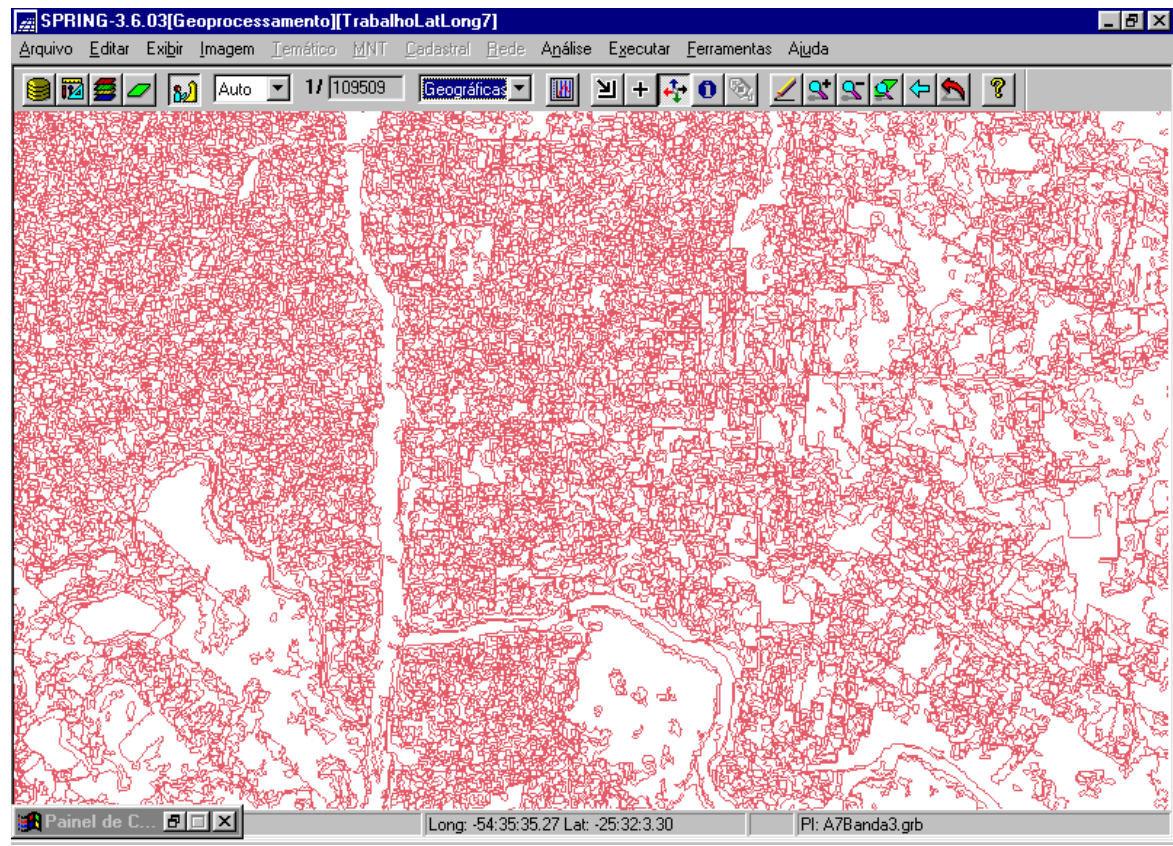

Figura 9. Imagem da região em estudo segmentada com zoom. 


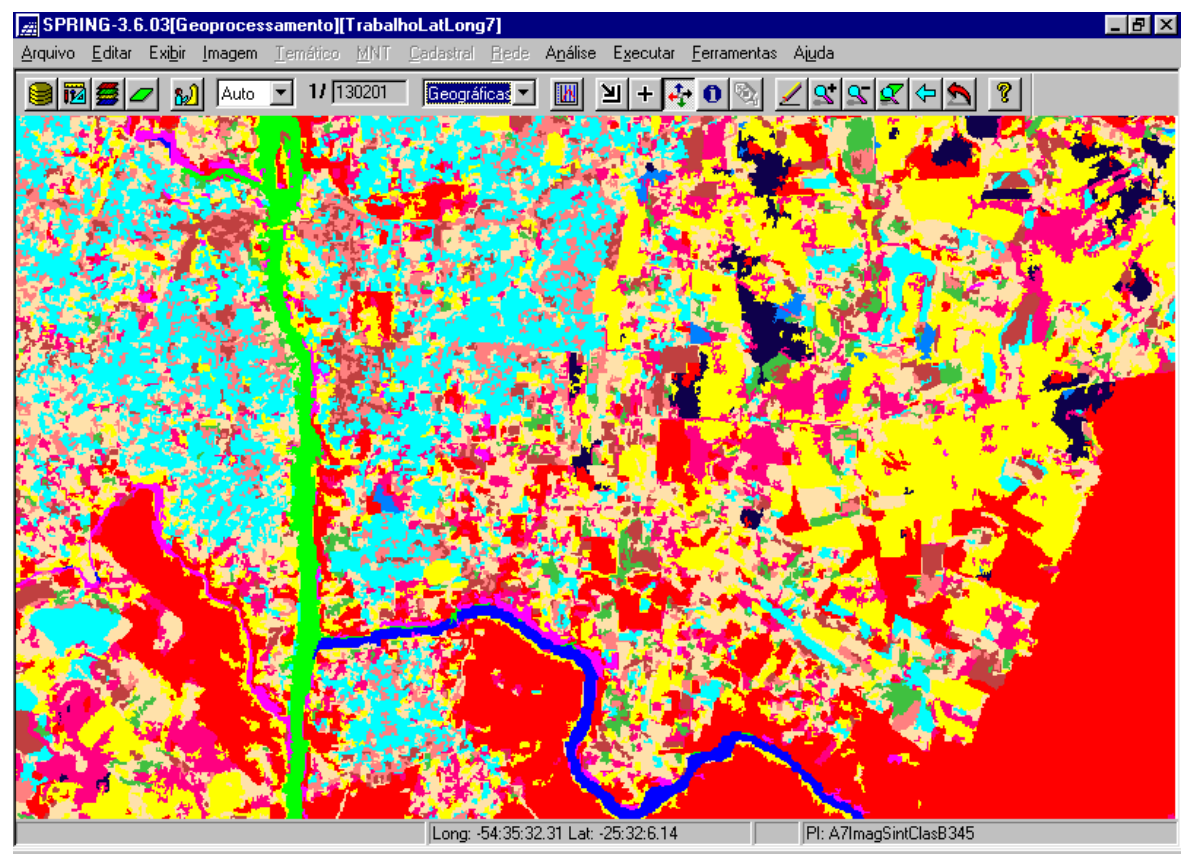

Figura 10. Imagem da região em estudo classificada com zoom.

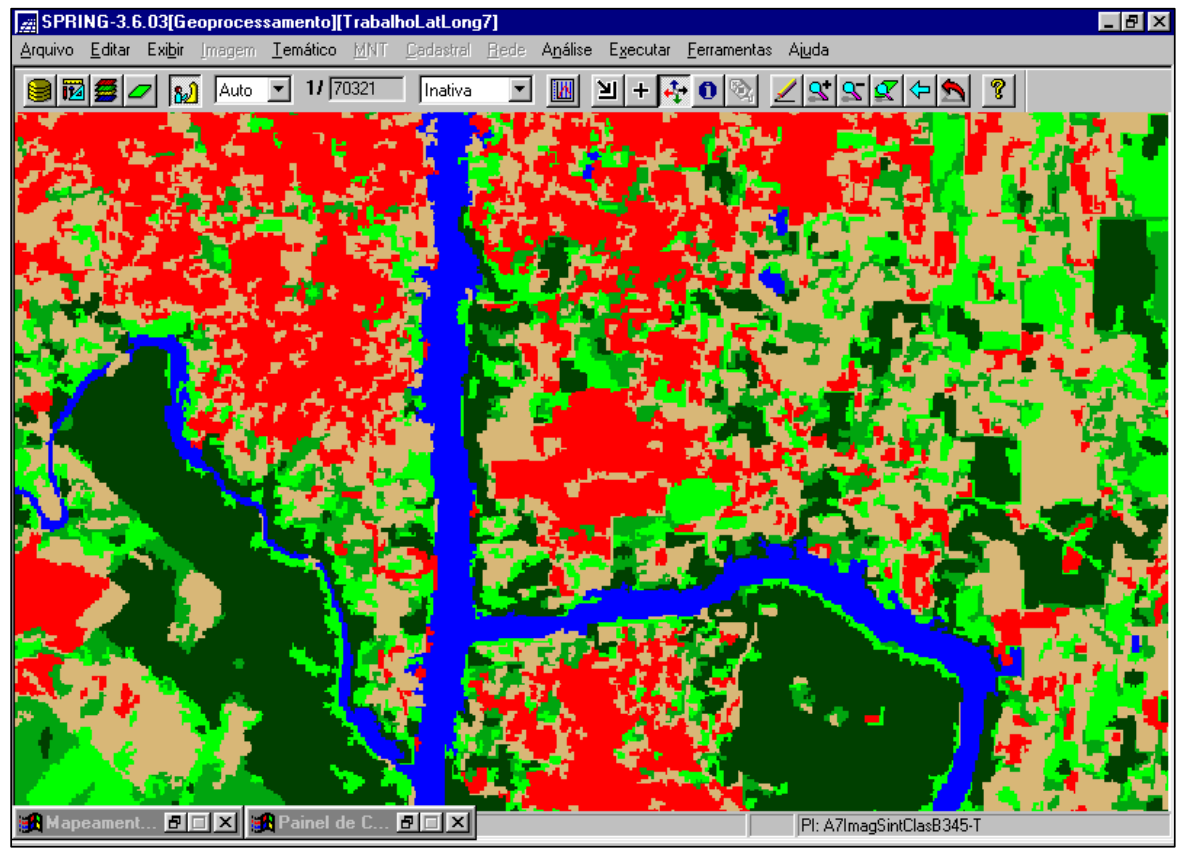

Figura 11 - Mapa temático da região em estudo com zoom.

Para a região em estudo o algoritmo Isoseg de classificação, não supervisionada de segmentos do Spring, mapeou 14 classes morfológicas.

Para criação do mapa temático, estas classes foram agrupadas de acordo com a Tabela IV.
O mapa temático com as classes morfológicas da região em estudo é apresentado na Fig. 11 com zoom. 
Tabela IV

AGREGAÇÃO DAS CLASSES MORFOLÓGICAS

\begin{tabular}{|c|c|c|c|}
\hline $\begin{array}{c}\text { Classes morfológicas } \\
\text { mapeadas }\end{array}$ & \multicolumn{2}{|c|}{$\begin{array}{c}\text { Classes morfológicas do } \\
\text { mapa temático }\end{array}$} \\
\hline 1 & Vermelho & 1 & Vegetação arbórea \\
\hline 2 & Verde claro & 6 & Água \\
\hline 3 & Azul médio & 6 & Água \\
\hline 4 & Amarelo & 3 & Vegetação rasteira \\
\hline 5 & Marrom & 5 & Solo exposto \\
\hline 6 & Azul claro & 4 & Área urbana \\
\hline 7 & Palha & 5 & Solo exposto \\
\hline 8 & Lilás & 6 & Água \\
\hline 9 & Verde médio & 5 & Solo exposto \\
\hline 10 & Azul escuro & 3 & Vegetação rasteira \\
\hline 11 & Laranja & 4 & Área urbana \\
\hline 12 & Azul petróleo & 3 & Vegetação rasteira \\
\hline 13 & Violeta & 2 & Vegetação arbustiva \\
\hline 14 & Verde escuro & 2 & Vegetação arbustiva \\
\hline
\end{tabular}

\section{CONCLUSÃO}

Para a realização deste trabalho foram utilizados recursos tecnológicos da área de sensoriamento remoto e geoprocessamento, resultando no mapeamento morfológico da região em estudo.

O método descrito possibilitou a identificação e a classificação da morfologia, alcançando assim o objetivo do trabalho, que foi mapear os recursos naturais e a ocupação do solo da região em estudo.

O conhecimento da região em estudo é imprescindível para ajuste fino do processamento e correlação entre as classes mapeadas e do mapa temático.

As bandas utilizadas, os parâmetros dos algoritmos de segmentação, de classificação e de identificação das classes mapeadas podem ser alterados a fim de melhorarem a exatidão dos resultados.

Processos de filtragem e operações aritméticas entre as imagens também podem agregar alguma melhoria.

Este método de mapeamento morfológico apresentou resultados satisfatórios na exatidão e agilidade, quando comparado com os métodos tradicionais de levantamento de informações manuais sem a utilização do sensoriamento remoto e do geoprocessamento.

Outras regiões com características diferentes poderão ser mapeadas de forma rápida e precisa utilizando-se este método.
À medida que o mesmo for sendo utilizado poder-se-á verificar suas potencialidades, conhecer suas limitações e aprimorar sua utilização, de forma a facilitar o processamento das informações.

\section{REFERÊNCIAS BIBLIOGRÁFICAS.}

[1] M. A. Moreira, "Fundamentos do Sensoriamento Remoto e Metodologias de Aplicação", UFV, 2003.

[2] A. H. Robson, J. L. Morrison, P. C. Muehrcke, A. J. Kimerling and S. C. Guptill, "Elements of Cartography", Sixth Edition, John Wiley \& Sons Inc, 1995.

[3] Sistemas de Processamento de Informações Georeferenciadas. Disponível em: http: // www. dpi. inpe. br/ spring/, visitado em 28/07/2007.

[4] S. S. Lopes, "Tutorial 10 aulas SPRING 3.6", INPE, 2002.

[5] "Brasil em Foco 2001 -Índice Target de Potencial de Consumo", Target Marketing, V 3.95.

[6] "Guia Brasil - Quatro Rodas", Ed. Abril, 1998.

[7] R. Simi, R. Simi Junior, J. V. Rech, e F. A. Anjos, XI SBSR, "Avaliação Ambiental da Porção Sul do Balneário Camboriú em Santa Catarina, através de Imagens Orbitais em Escalas 1:20.000 e 1:10.000, para fins de Planejamento Territorial Costeiro", INPE, 2003.

[8] L. Moreira e E. D. Assad, "Segmentação e Classificação Supervisionada no Uso da Terra na Microbacia do Córrego Lamarão D.F.", Embrapa, 1997.

[9] A. Luchiari, "Identificação da Cobertura Vegetal e Áreas Urbanas por meio de Produtos de Sensoriamento Remoto e de um Sistema de Informação Geográfica", Revista do Departamento de Geografia, 14 (2001), pags. 47-58.

[10] O. R. Vergara, M. L. N. O. Kurkdjian, J. C. L. D'Alge e M. N. Pereira, "Conteúdo Informativo e Exatidão 
Geométrica de Dados TM-Landsat Analógicos para Atualização de Cartas Topográficas", INPE, 1999.

[11] A. L. Ruhoff, Revista Eletrônica do Mestrado em Educação Ambiental FUFRG, "Diagnóstico Ambiental do Municipio de Sinimbu, RS numa Abordagem Integrada da Paisagem", Vol 09, Jul-Dez 2002.

[12] Disponível em Engesat: www. engesat. com. br/, visitado em 28/06/2007.

[13] Disponível em Mosaico do Brasil: www.dpi.inpe.br/mosaico, visitado em 28/06/2007. 